ORIGINAL ARTICLE

\title{
Who waits longest in the emergency department and who leaves without being seen?
}

\author{
S Goodacre, A Webster
}

Emerg Med J 2005;22:93-96. doi: 10.1136/emj.2003.007690

\begin{abstract}
Objectives: To determine which patient characteristics are associated with prolonged waiting times in the emergency department and which characteristics are associated with an increased risk of leaving without being seen.

Methods: Multivariate analysis of routine data collected at the Northern General Hospital, Sheffield between 1 January and 31 December 2001. Patient age, sex, triage priority, postcode, initiator of attendance, mode of arrival, time, day, and month of presentation were examined as potential predictors of waiting time and risk of leaving without being seen.

Results: Waiting time data for 71331 patients were analysed, along with a further 5512 patients who left without being seen. Older patients and those with lower triage priority had longer waiting times, while ambulance borne patients had slightly shorter waiting times. Sex, source of referral, and postcode did not predict waiting times. The most powerful predictors of waiting time related to time of presentation, with longer waits being associated with presentation at night, on Mondays or Sundays, and during autumn months. Patients who left without being seen were more likely to be younger, male, lower triage priority, non-ambulance borne, self referred, and presenting at the times when waiting times were longest.

Conclusion: Time of presentation, rather than individual patient characteristics, seem to be the most powerful predictors of waiting time. This suggests that concerns about inequity of waiting times should be addressed by reorganisation of staff duty rosters.
\end{abstract}

See end of article for authors' affiliations

Correspondence to: Dr S Goodacre, 87A Sydney Road, Sheffield S6 3GG,UK; s.goodacre@ sheffield.ac.uk

Accepted for publication 13 June 2003
$\mathrm{P}$ rolonged waiting times for patients in the emergency department are associated with reduced patient satisfaction $^{1}$ and an increased risk of leaving without being seen. ${ }^{2}$ This in turn is associated with high rates of representation and poorer health outcomes. ${ }^{2}$ Waiting times have been increasing in the United Kingdom ${ }^{3}$ and have been identified as a priority area by the UK Department of Health. ${ }^{45}$ As a result a number of initiatives have been introduced in an attempt to tackle this problem. ${ }^{67}$

It is clearly important to reduce waiting times, yet it is highly unlikely that current initiatives will abolish waits completely. It is therefore also important that waiting times are equitable for individual patients. That is, differences in individual patients' waiting times should be, as far as possible, related only to clinical need. Waiting times act as a barrier to access to health care, and equity of access to health care is an important goal for the NHS. ${ }^{8}$

Data from Australia9 suggest that waiting times are not equitable and that women, non-English speaking patients, self referred patients, or patients with a lower socioeconomic status are more likely to wait longer. To our knowledge, no study has yet attempted to discover if these findings are reproduced in the UK. The aim of this study was therefore to identify factors predicting prolonged waiting times for patients attending our emergency department and factors predicting which patients are most likely to leave without being seen.

\section{METHODS}

The Northern General Hospital emergency department is the only emergency department serving the adult population of Sheffield, United Kingdom (population 530 000). About 90000 adults attend the department each year. Upon attendance patients are categorised into five triage categories: immediate (category one), very urgent (category two), urgent (category three), standard (category four), and non-urgent (category five).

Data relating to new attendances presenting between 1 January and 31 December 2001 were analysed. Patients were excluded if they were a direct referral to an inpatient team, if they were brought in dead, or if their data were incomplete. Patients were also excluded from analysis of waiting times if they did not wait to be seen.

The following patient characteristics were examined as potential predictors of waiting time and leaving without being seen: age, sex, postcode (S5 or S10), triage category, initiator of attendance (general practitioner or other), mode of arrival (ambulance or other), time of attendance, day of attendance, and month of attendance.

The S5 and S10 postcodes were chosen to explore two separate hypotheses. Firstly, the hospital lies within the S5 postal district, so this characteristic was used to test the hypothesis that living close to the hospital might predict waiting time or leaving without being seen. Secondly, the S10 postal district is more affluent than the rest of Sheffield, so this characteristic was used to test the hypothesis that affluence might be predictive of waiting time or leaving without being seen.

For each characteristic the mean waiting time and the proportion that left without being seen were calculated. Univariate analysis was used to see if the characteristic was significantly associated with waiting time or leaving without being seen. Significance was set at 0.05. All univariate predictors of outcome were then entered into multivariate models to determine which characteristics were independent predictors of waiting time or leaving without being seen.

Univariate analysis for waiting times was undertaken using an independent sample $t$ test for binary variables, one way analysis of variance for categorical variables with multiple categories, and linear regression for continuous variables. Multivariate analysis for waiting times was 
undertaken using linear regression. Categorical variables with multiple categories were converted into multiple binary variables. The category with the shortest waiting times on univariate analysis was selected to be the reference category. Univariate analysis for leaving without being seen was undertaken using a $\chi^{2}$ test for categorical variables and logistic regression for continuous variables. Multivariate analysis was undertaken using logistic regression. Categorical variables with multiple categories were handled as outlined above. All analyses were undertaken using SPSS for Windows, version 10 (SPSS, Chicago, IL).

\section{RESULTS}

There were 79437 new attendances during 2001. Of these, 1705 were direct referrals to inpatient teams, 56 were brought in dead, 833 had incomplete data, and 5512 left before they were seen. Thus 76843 cases were included in the analysis of leaving without being seen and 71331 cases were included in the analysis of waiting times.

The mean waiting time for all patients was 84.7 minutes (median 71.0, SD 64.7). There were 41979 men (54.6\%) and 34864 women $(45.4 \%)$, and the mean age was 45.3 years. Patients were triaged as follows: $432(0.6 \%)$ to triage category one, $1916(2.5 \%)$ to category two, $29291(38.1 \%)$ to category three, $43141(56.1 \%)$ to category four, and $2063(2.7 \%)$ to category five. There were $3486(4.5 \%)$ GP initiated attendances, while 25567 (33.3\%) arrived by ambulance. Patients presented at the following times: 10338 (13.5\%) between midnight and $600 \mathrm{am}, 18478(24.0 \%)$ between $600 \mathrm{am}$ and midday, 26217 (34.1\%) between midday and $600 \mathrm{pm}$, and $21810(28.4 \%)$ between $600 \mathrm{pm}$ and midnight.

The following characteristics were predictive of waiting time on univariate analysis: age, triage category, initiator of attendance, mode of arrival, time of presentation, day of attendance, and month of attendance (all $\mathrm{p}<0.001)$. Sex $(p=0.067)$, S5 postcode $(p=0.351)$, and $S 10$ postcode $(\mathrm{p}=0.877)$ were not predictive. Table 1 shows the results of multivariate analysis. The coefficient for each characteristic represents the effect of that characteristic upon waiting time, compared with the reference category. So, for example, patients attending on Monday are predicted to wait 23 minutes longer than those attending on Friday (the reference category).

The following characteristics were predictive of leaving without being seen on univariate analysis: age, sex, triage category, initiator of attendance, mode of arrival, time of presentation, day of attendance, and month of attendance (all $\mathrm{p}<0.001)$. S5 postcode $(\mathrm{p}=0.688)$ and S10 postcode $(p=0.207)$ were not predictive. Table 2 shows the results of multivariate analysis. The odds ratio for each characteristic represents the odds of leaving without being seen for that category, compared with the reference category. As the prevalence of leaving without being seen is $7.2 \%$ the odds ratio will only slightly over-estimate the relative risk. So, for example, men are about $18 \%$ more likely to leave without being seen than women.

Table 1 Multivariate analysis of waiting time to see doctor or nurse practitioner

\begin{tabular}{|c|c|c|c|c|}
\hline Characteristic & $\begin{array}{l}\text { Mean waiting } \\
\text { time (min) }\end{array}$ & Coefficient & $95 \% \mathrm{Cl}$ & p Value \\
\hline Age & - & $0.027^{*}$ & 0.005 to 0.049 & 0.016 \\
\hline \multicolumn{5}{|l|}{ Triage category } \\
\hline 1 & 4.8 & Reference & - & - \\
\hline 2 & 31.1 & 27.5 & 21.1 to 33.8 & $<0.001$ \\
\hline 3 & 83.1 & 78.2 & 72.4 to 83.9 & $<0.001$ \\
\hline 4 & 89.0 & 85.4 & 79.6 to 91.2 & $<0.001$ \\
\hline 5 & 86.8 & 88.1 & 81.7 to 94.6 & $<0.001$ \\
\hline \multicolumn{5}{|c|}{ Initiator of attendance } \\
\hline GP & 80.6 & 1.1 & -1.0 to 3.1 & 0.300 \\
\hline Other & 79.4 & Reference & - & - \\
\hline \multicolumn{5}{|l|}{ Arrival by } \\
\hline Ambulance & 78.7 & Reference & - & - \\
\hline Other & 87.7 & 8.7 & 6.9 to 10.4 & $<0.001$ \\
\hline \multicolumn{5}{|c|}{ Time of presentation } \\
\hline $00: 00$ to $06: 00$ & 113.6 & 45.0 & 43.5 to 46.6 & $<0.001$ \\
\hline $06: 00$ to $12: 00$ & 71.0 & Reference & - & - \\
\hline $12: 00$ to $18: 00$ & 79.9 & 8.3 & 7.2 to 9.5 & $<0.001$ \\
\hline $18: 00$ to $00: 00$ & 88.8 & 18.6 & 17.4 to 19.8 & $<0.001$ \\
\hline \multicolumn{5}{|c|}{ Day of attendance } \\
\hline Monday & 96.0 & 23.3 & 21.7 to 24.9 & $<0.001$ \\
\hline Tuesday & 81.6 & 8.8 & 7.2 to 10.5 & $<0.001$ \\
\hline Wednesday & 77.7 & 5.3 & 3.6 to 6.9 & $<0.001$ \\
\hline Thursday & 80.6 & 8.1 & 6.5 to 9.7 & $<0.001$ \\
\hline Friday & 72.3 & Reference & - & - \\
\hline Saturday & 86.0 & 11.3 & 9.6 to 12.9 & $<0.001$ \\
\hline Sunday & 96.1 & 21.3 & 19.7 to 23.0 & $<0.001$ \\
\hline \multicolumn{5}{|c|}{ Month of attendance } \\
\hline January & 82.0 & 11.6 & 9.5 to 13.7 & $<0.001$ \\
\hline February & 71.4 & 1.0 & -1.1 to 3.2 & 0.349 \\
\hline March & 71.9 & 1.7 & -0.4 to 3.8 & 0.112 \\
\hline April & 79.8 & 8.2 & 6.1 to 10.3 & $<0.001$ \\
\hline May & 70.4 & Reference & - & - \\
\hline June & 72.1 & 1.4 & -0.7 to 3.4 & 0.196 \\
\hline July & 78.9 & 7.0 & 5.0 to 9.0 & $<0.001$ \\
\hline August & 88.4 & 18.2 & 16.1 to 20.3 & $<0.001$ \\
\hline September & 107.3 & 35.9 & 33.8 to 38.0 & $<0.001$ \\
\hline October & 112.3 & 41.4 & 39.3 to 43.5 & $<0.001$ \\
\hline November & 90.5 & 20.3 & 18.2 to 22.4 & $<0.001$ \\
\hline December & 91.1 & 20.1 & 18.0 to 22.2 & $<0.001$ \\
\hline
\end{tabular}




\begin{tabular}{|c|c|c|c|c|}
\hline Characteristic & $\begin{array}{l}\text { Proportion } \\
\text { who did not } \\
\text { wait }\end{array}$ & Odds ratio & $95 \% \mathrm{Cl}$ & $\mathrm{p}$ Value \\
\hline Age & - & $0.978^{*}$ & 0.976 to 0.980 & $<0.001$ \\
\hline Male sex & 8.3 & 1.18 & 1.11 to 1.25 & $<0.001$ \\
\hline \multirow{2}{*}{\multicolumn{5}{|c|}{$\begin{array}{l}\text { Female sex } \\
\text { Triage category }\end{array}$}} \\
\hline & & & & - \\
\hline 2 & 0.3 & 4.0 & 0.1 to 119 & 0.429 \\
\hline 3 & 3.2 & 34.0 & 1.2 to 939 & 0.037 \\
\hline 4 & 9.4 & 89.0 & 3 to 2452 & 0.008 \\
\hline 5 & 25.0 & 376.5 & 14 to 10402 & $<0.001$ \\
\hline \multicolumn{5}{|c|}{ Initiator of attendance } \\
\hline GP & 3.1 & 0.68 & 0.56 to 0.83 & $<0.001$ \\
\hline Other & 7.4 & Reference & - & - \\
\hline \multicolumn{5}{|l|}{ Arrival by } \\
\hline Ambulance & 3.6 & 0.57 & 0.51 to 0.64 & $<0.001$ \\
\hline Other & 8.9 & Reference & - & - \\
\hline \multicolumn{5}{|c|}{ Time of presentation } \\
\hline $00: 00$ to $06: 00$ & 13.8 & 4.49 & 4.06 to 4.97 & $<0.001$ \\
\hline $06: 00$ to $12: 00$ & 3.7 & Reference & - & - \\
\hline $12: 00$ to $18: 00$ & 5.8 & 1.53 & 1.40 to 1.69 & $<0.001$ \\
\hline $18: 00$ to $00: 00$ & 8.6 & 2.42 & 2.21 to 2.66 & $<0.001$ \\
\hline \multicolumn{5}{|c|}{ Day of attendance } \\
\hline Monday & 8.1 & 1.57 & 1.41 to 1.76 & $<0.001$ \\
\hline Tuesday & 6.5 & 1.19 & 1.06 to 1.34 & 0.003 \\
\hline Wednesday & 5.5 & Reference & - & - \\
\hline Thursday & 6.6 & 1.20 & 1.07 to 1.35 & 0.002 \\
\hline Friday & 6.2 & 1.11 & 0.99 to 1.26 & 0.080 \\
\hline Saturday & 8.2 & 1.38 & 1.24 to 1.55 & $<0.001$ \\
\hline Sunday & 8.9 & 1.54 & 1.38 to 1.73 & $<0.001$ \\
\hline \multicolumn{5}{|c|}{ Month of attendance } \\
\hline January & 6.3 & 1.25 & 1.07 to 1.46 & 0.005 \\
\hline February & 5.4 & 1.05 & 0.89 to 1.23 & 0.582 \\
\hline March & 5.3 & Reference & - & - \\
\hline April & 6.0 & 1.15 & 0.99 to 1.35 & 0.072 \\
\hline May & 5.8 & 1.08 & 0.93 to 1.26 & 0.312 \\
\hline June & 6.0 & 1.12 & 0.96 to 1.31 & 0.161 \\
\hline July & 6.8 & 1.29 & 1.11 to 1.50 & 0.001 \\
\hline August & 8.2 & 1.69 & 1.46 to 1.96 & $<0.001$ \\
\hline September & 10.3 & 2.14 & 1.85 to 2.47 & $<0.001$ \\
\hline October & 11.1 & 2.42 & 2.10 to 2.78 & $<0.001$ \\
\hline November & 7.0 & 1.41 & 1.21 to 1.65 & $<0.001$ \\
\hline December & 7.5 & 1.60 & 1.38 to 1.86 & $<0.001$ \\
\hline
\end{tabular}

\section{DISCUSSION}

As expected, triage category was an independent predictor of waiting time, although it is striking that this was effectively limited to triage categories one and two. Waiting times for triage categories three to five were very similar. After adjustment for triage category, older patients tended to wait longer, ambulance borne patients waited less, while GP referral did not effect waiting time. However, the effects of age and ambulance transport were of little clinical significance. Sex and postcode did not predict waiting times. Hence we found no evidence that the patient characteristics identified in the Australian study ${ }^{9}$ were important predictors of prolonged waiting times in the UK.

The most important factors affecting waiting time were related to time of presentation. Patients presenting between midnight and 600 am were predicted to wait 45 minutes longer than those presenting between $600 \mathrm{am}$ and midday. Patients presenting on Monday or Sunday were predicted to wait more than 20 minutes longer than those presenting on Friday. Patients presenting during the autumn also had longer waiting times, although as this study reports data from only one year it is not clear whether this finding was specific to 2001 .

Triage categorisation also predicted the likelihood of leaving without being seen. Indeed it is striking that one quarter of category five patients left without being seen. This may explain why waiting times for categories four and five were not too much longer than those for category three. It seems that the lower triage categories may be used as a tool for diverting patients away from the emergency department, rather than prolonging their waiting time.

Patients were also more likely to leave without being seen if they were younger or male, while those who were referred by their GP or arrived by ambulance were less likely to leave. Times of presentation associated with longer waiting times were also associated with a higher probability of leaving without being seen. We were unable to adjust for expected waiting time in this analysis, but it would seem likely that prolonged waiting times at time of presentation would predict a higher probability of leaving without being seen. We were also unable to adjust for other factors, such as alcohol consumption, that might explain why younger patients, men, and those presenting at night are more likely to leave without being seen.

In addition to the limitations outlined above, it should also be recognised that these data originate from only one emergency department and may not be generalisable elsewhere. In particular, the Northern General Hospital is an adults only hospital, so findings cannot be generalised to the paediatric population, the process of triage categorisation may differ from processes used elsewhere, and the pattern of patient presentation may be specific to a large, urban emergency department.

A number of potential solutions to the problems of prolonged waiting times have been proposed and evaluated. ${ }^{67^{10}}$ These interventions have generally attempted to 
reduce overall waiting times for all patients. In doing this there has been occasional criticism that some approaches may risk increasing inequity by reducing the waiting times of the more numerous patients with "minor" complaints, at the expense of those with more complex problems. ${ }^{11}$

Our data suggest that time of presentation may already be a far more important determinant of equity. Improving equity of waiting times would therefore require more staff to be employed at night time and weekends. Yet such an approach may compromise efficiency because most emergency department staff are more costly to employ during antisocial hours. Trade offs between equity and efficiency in health care have been described elsewhere, ${ }^{12}$ but not to date (to our knowledge) in relation to emergency department waiting times. This finding is important because crude measures of waiting time, such as the proportion seen within an hour, may promote efficiency at the expense of equity.

\section{Authors' affiliations}

S Goodacre, Andrew Webster, Emergency Department, Northern General Hospital, Sheffield, UK

Funding: none.

Conflicts of interest: none.

\section{REFERENCES}

1 Spaite DW, Bartholomeaux F, Guisto J, et al. Rapid process redesign in a university-based emergency department: decreasing waiting time intervals and improving patient satisfaction. Ann Emerg Med 2002;39:168-77.

2 Bindman AB, Grumbach K, Keane D, et al. Consequences of queuing for care at a public hospital emergency department. JAMA 1991;266:1091-6.

3 Audit Commission. Acute hospital portfolio review of national findings: accident and emergency. London: The Audit Commission, 2001.

4 Department of Health. The NHS plan. London: Department of Health, 2000.

5 Department of Health. Reforming emergency care. London: Department of Health, 2001

6 Cooke MW, Wilson S, Pearson S. Fast tracking of minor injuries. Emerg Med J 2003; 19:28-30.

7 Lammy D. Reforming emergency care; for patients. Emerg Med J 2003;20:112.

8 Gulliford M, Hughes D, Figeroa-Munoz J, et al. Access to health care. Report of a scoping exercise for the National Co-ordinating Centre for NHS Service Delivery and Organisation R\&D (NCCSDO). London: Department of Health, 2001.

9 Mohsin M, Bauman A, leraci S. Is there equity in emergency care? Waiting times and walk-outs in South Western Sydney hospital emergency departments. Australian Health Review 1998;21:133-49.

10 Fernandes CM, Christenson JM. Use of continuous quality improvement to facilitate patient flow through the triage and fast-track areas of an emergency department. J Emerg Med 1995; 13:847-55.

11 Windle J, Mackway-Jones K. Don't throw triage out with the bathwater. Emerg Med J 2003:20:1 19-20.

12 Sassi F, Archard L, Le Grand J. Equity and the economic evaluation of health care. Health Technol Assess 2001;5. 